\title{
BMJ Open Impact of community-based chronic obstructive pulmonary disease service, a multidisciplinary intervention in an area of high deprivation: a longitudinal matched controlled study
}

\author{
Pooja Saini (D) , ${ }^{1}$ Tanith Rose, ${ }^{2}$ Jennifer Downing, ${ }^{3}$ Bashir Matata, ${ }^{4}$ \\ Samantha Pilsworth, ${ }^{5}$ Allan Pemberton, ${ }^{5}$ Terence Comerford, ${ }^{5}$ Keith Wilson, ${ }^{5}$ \\ Matthew Shaw, ${ }^{6}$ Lesley M Harper, ${ }^{7}$ Konstantinos Daras, ${ }^{2}$ Benjamin Barr ${ }^{2}$
}

To cite: Saini P, Rose T, Downing J, et al. Impact of community-based chronic obstructive pulmonary disease service, a multidisciplinary intervention in an area of high deprivation: a longitudinal matched controlled study. BMJ Open 2020;10:e032931. doi:10.1136/ bmjopen-2019-032931

- Prepublication history and additional material for this paper are available online. To view these files, please visit the journal online (http://dx.doi. org/10.1136/bmjopen-2019032931).

PS and TR are joint first authors.

Received 13 July 2019 Revised 03 March 2020 Accepted 17 April 2020

A) Check for updates

(C) Author(s) (or their employer(s)) 2020. Re-use permitted under CC BY-NC. No commercial re-use. See rights and permissions. Published by BMJ.

For numbered affiliations see end of article.

Correspondence to

Dr Pooja Saini;

P.Saini@ljmu.ac.uk

\section{ABSTRACT}

Objective To examine the effects of a consultant-led, community-based chronic obstructive pulmonary disease (COPD) service, based in a highly deprived area on emergency hospital admissions.

Design A longitudinal matched controlled study using difference-in-differences analysis to compare the change in outcomes in the intervention population to a matched comparison population, 5 years before and after implementation.

Setting A deprived district in the North West of England between 2005 and 2016.

Intervention A community-based, consultant-led COPD service providing diagnostics, treatment and rehabilitation from 2011 to 2016.

Main outcome measures Emergency hospital admissions, length of stay per emergency admission and emergency readmissions for COPD.

Results The intervention was associated with 24 fewer emergency COPD admissions per 100000 population per year $(95 \% \mathrm{Cl}-10.6$ to $58.8, \mathrm{p}=0.17)$ in the postintervention period, relative to the control group. There were significantly fewer emergency admissions in populations with medium levels of deprivation (64 per 100 000 per year; $95 \% \mathrm{Cl} 1.8$ to 126.9 ) and among men (60 per 100000 per year; $95 \% \mathrm{Cl} 12.3$ to 107.3).

Conclusion We found limited evidence that the service reduced emergency hospital admissions, after an initial decline the effect was not sustained. The service, however, may have been more effective in some subgroups.

\section{BACKGROUND}

Chronic obstructive pulmonary disease (COPD) is one of the leading causes of death, hospital readmission and cost to society in the UK, responsible for $5 \%$ of all deaths and one-third of all deaths when including lung disease. ${ }^{1-3}$ An estimated 1.2 million people are living with diagnosed COPD which is considerably more than the 835 000 estimated by the Department of Health
Strengths and limitations of this study

Within this study, we calculated the Knowsley chronic obstructive pulmonary disease (KCOPD) service in its real-life implementation setting, which makes our findings potentially more externally valid than those set in a trial context.

- The KCOPD service has been in operation for several years giving a long follow-up period of 5 years; thus allowing us to look at whether effects were sustained.

- For this study, we applied a combination of quasiexperimental methods-propensity score matching and difference-in-differences, which provide causal estimates of the intervention if the trends in outcomes would have been parallel in the absence of the intervention.

- We were only able to assess the impact of the intervention of emergency hospital admissions and this may not reflect health benefits to the users of these services.

- The ecological nature of this study limits the conclusions that can be drawn about individual-level factors, and the results reflect the population-level impact of the KCOPD service.

in 2011. ${ }^{14}$ The burden of COPD disproportionally effects disadvantaged socioeconomic groups with rates in the most deprived areas of the population twice as high as in the least deprived. $^{5-7}$ The prevalence of COPD has increased by $27 \%$ over the last decade ${ }^{4}$ and the burden on health services is increasing as the population ages. The costs of COPD to the National Health Service (NHS) in England is over $£ 800$ million, with an additional $£ 3.8$ billion in lost productivity, and is estimated to increase annually. These costs to the NHS are unsustainable. Improving the identification and treatment of COPD, while 
reducing emergency admissions and length of inpatient stay, has been highlighted as a priority for the NHS in its Five-Year Forward View. ${ }^{8}$ The NHS Long Term Plan ${ }^{9}$ also aims to tackle health inequalities between the most and least deprived, and highlights that cause of death from respiratory diseases is the second largest contributor to the life expectancy gap between these groups. There is, therefore, an urgent need for evidence of effective interventions that improve the management of COPD and reduce unplanned emergency admissions, particularly in disadvantaged populations.

COPD may be preventable by avoidance or early cessation of smoking, particularly within deprived communities where there is a higher prevalence of smoking. ${ }^{10}$ However, access to smoking cessation services has reduced in recent years; only a quarter of COPD patients admitted to hospital were asked about their smoking status and subsequently offered the service. ${ }^{3}$ Existing evidence shows that rapid access pulmonary rehabilitation (PR) clinics provide efficient and effective substitution to COPD clinic assessment. ${ }^{11}{ }^{12}$ Yet, there are examples to indicate that secondary care-based rapid access clinics may be underused by older populations and those in poorer socioeconomic circumstances. ${ }^{13}$ This could potentially be due to problems with access, however, there is limited published evidence investigating the provision of rapid access clinics in community settings. Communitybased PR services have been found to improve access and reduce emergency admissions ${ }^{14-16}$ and be cost-effective. ${ }^{15}$ Community-based PR shows that it is as effective and safe as hospital-based rehabilitation and has been associated with reduced length of hospital stay, reduced mortality rates and improved health-related quality of life with COPD patients who recently suffered an exacerbation of COPD. ${ }^{11}$ While there is some case study evidence for community-based consultant-led services, ${ }^{17}$ there is limited evidence for consultant-led COPD-communitybased clinics. Although there is evidence for multicomponent approaches to reduce hospital admissions for single conditions, ${ }^{18}$ there is a lack of evidence for consultant-led community-based integrated COPD services in deprived communities.

To address these gaps in the evidence base, we investigated the impact on emergency hospital admissions of a consultant-led, community-based 'one-stop' COPD service implemented in a very deprived community in the North West of England; particularly as there has been a significant proportion of undiagnosed COPD reported in this area. ${ }^{19}$ The service brought together diagnostic, treatment, management and rehabilitation services for COPD, offering a rapid response service within 13 hours that would usually be provided in secondary care. We examined the impact of this service on emergency admissions, length of inpatient stay and readmissions.
METHODS

\section{Setting}

The intervention was implemented between 2011 and 2016 across the district of Knowsley in the North West of England, which has a population of $148560^{20}$ and is the second most deprived district in England based on the Indices of Multiple Deprivation. ${ }^{21}$ There is a history of industrial exposure, for example, mining, manufacturing, shipping and dock work; however, comparisons between areas in Knowsley have shown no increase for the rate of hospital admissions where there was evidence of this exposure. ${ }^{22}$

\section{Study design}

This study was a longitudinal matched controlled study using lower super output areas (LSOA) as the unit of analysis. LSOAs are small geographical areas used by the UK's Office for National Statistics (ONS), each typically containing a population of about 1500 people. England is divided into just over 30000 LSOAs. Ninety-Eight LSOAs cover the entire population of the intervention area-Knowsley. Each of these intervention LSOAs were matched with four control LSOAs located within other districts in the North West region of England, providing 392 matched control LSOAs, that is, 490 LSOAs in total. We used propensity score matching ${ }^{23}$ to ensure that these control areas had similar observed characteristics to the Knowsley LSOAs in the time period before the introduction of the intervention (2005-2010). The matching was based on the gender and age profile of the population, unemployment rate, Indices of Multiple Deprivation, COPD emergency admission rate, prevalence of COPD, smoking prevalence, proportion of COPD patients who have had their inhaler technique checked, numbers of general practitioners (GPs) per capita serving the population and the distance to the nearest GP practice and hospital (see table 1/ online supplementary appendix 1 for full details of the matching variables). The nearest neighbour method was used for matching, which selects controls with propensity scores that are closest to that of the intervention LSOAs. ${ }^{24}$ We checked with the regional COPD network that no other similar intervention was implemented in the North West and, therefore, our control populations would not have experienced a similar intervention.

We then compared the change (difference) in outcomes in the intervention population to the change (difference) in outcomes in a matched comparison population, 6 years before and 5 years after implementation. This difference-in-differences method controls for all time-invariant differences between the intervention and control populations. The key assumption of differencein-differences analysis is the parallel trends assumption. If the trend in the outcome in the intervention and control populations would have been parallel in the absence of the intervention then, the difference between the change in the outcomes between the two groups provides an unbiased estimate of the interventions effect ${ }^{25}$ (see online 
Table 1 Description of matching variables

Matching variable Details

Age and gender profile of the population

Unemployment rate

Annual data on the size of the female population and the population aged $50+$ years per lower super output area (LSOA) were derived from midyear population estimates provided by the Office for National Statistics (ONS).

Annual unemployment rates were calculated using claimant data provided by the ONS. Unemployment was measured as the proportion of people aged 16-64 years claiming Jobseeker's Allowance or Universal Credit principally for the reason of being unemployed.

\begin{tabular}{|c|c|}
\hline $\begin{array}{l}\text { Chronic obstructive pulmonary } \\
\text { disease (COPD) emergency } \\
\text { admission rate }\end{array}$ & $\begin{array}{l}\text { Emergency admissions for COPD were defined using ICD-10 codes: J40-J44. Annual } \\
\text { COPD emergency admission rates per } 100000 \text { population were calculated using } \\
\text { Hospital Episode Statistics, with population data obtained from the ONS. Continuous } \\
\text { inpatient spells were used to calculate emergency admissions per calendar year. }\end{array}$ \\
\hline Indices of Multiple Deprivation & $\begin{array}{l}\text { Index of Multiple Deprivation } 2015 \text { data were provided by the Department for } \\
\text { Communities and Local Government. }\end{array}$ \\
\hline $\begin{array}{l}\text { Quality and outcomes framework } \\
\text { (QOF) indicators }\end{array}$ & $\begin{array}{l}\text { QOF indicator data for the prevalence of COPD and smoking, and the percentage of } \\
\text { patients with COPD receiving inhaled treatment whose inhaler technique had been } \\
\text { checked within the previous } 15 \text { months were included in the propensity score model. } \\
\text { Weighted averages of QOF indicators per LSOA were calculated using data provided by } \\
\text { NHS Digital on the number of patients registered per general practice per LSOA. }\end{array}$ \\
\hline $\begin{array}{l}\text { Numbers of general practitioners } \\
\text { (GPs) per capita serving the } \\
\text { population }\end{array}$ & $\begin{array}{l}\text { Weighted averages of the number of full-time employed GPs per } 1000 \text { population were } \\
\text { calculated using data provided by NHS Digital on the no of GPs and patients registered } \\
\text { per general practice per LSOA. }\end{array}$ \\
\hline $\begin{array}{l}\text { Distance to the nearest general } \\
\text { practice and hospital }\end{array}$ & $\begin{array}{l}\text { The Consumer Data Research Centre provided data per LSOA on the average road } \\
\text { network distance to the nearest hospital with an Accident and Emergency department, } \\
\text { and the nearest general practice. Road network distances in kilometres were calculated } \\
\text { by deriving the fastest route by car to travel from each postcode within an LSOA to the } \\
\text { nearest health service. }\end{array}$ \\
\hline
\end{tabular}

The following variables were included in a propensity score model to match Knowsley to control areas in the time period before the introduction of the intervention (2005-2010).

NHS, National Health Service.

supplementary appendix 2), for an outline of differencein-differences methods. We investigate this assumption by testing for parallel trends between the two groups prior to the intervention.

\section{Data sources and measures}

We used anonymised Hospital Episode Statistics (HES) and ONS population estimates to derive our primary outcome COPD (ICD-10 codes: J40-J44) emergency hospital admissions per 100000 population for each of the 490 LSOAs between 2005 and 2016, giving a total sample size of 5880 LSOA-years. ${ }^{26}{ }^{27}$ We chose to investigate COPD specific admissions, since all-cause admissions would likely be affected by other interventions occurring concurrently in Knowsley (eg, a cardiovascular disease (CVD) service intervention).$^{28}$ Emergency admissions were defined as admissions that are unpredictable and occur at short notice because of clinical need, as per the HES data dictionary. ${ }^{29}$ Secondary outcomes were length of stay per emergency admission and emergency readmission rates also derived from HES data. Readmissions were defined as emergency admissions occurring within 30 days of the last, previous discharge from hospital. ${ }^{30}$ To adjust for time varying factors that could be associated with trends in COPD emergency admission rates we controlled for the annual per cent of the population aged 50+years, the per cent female and the per cent unemployed using data obtained from the ONS.

\section{The service}

Prior to the implementation of the Knowsley COPD service (KCOPD), the Knowsley population was served by a COPD service run from two local district general hospitals (DGH) and a community service. One DGH provided consultant-led clinics from the hospital and one community clinic a week; it also provided a nurse-led ESD service and oxygen service. A separate community service provided community reviews for patients experiencing an exacerbation of COPD, it was not, however, an admission avoidance service. These services were provided on a Monday to Friday basis only. The PR service was provided by a second DGH and there was no additional support for chest clearance, breathlessness management.These services were provided by different organisations and were transferred to a single provider just before KCOPD was developed in 2011.

The KCOPD provided a new integrated 'one-stop' consultant-led service with diagnostics in the community, 
covering initially five different community venues, extending to seven over the course of the service and now covering 6 days a week and one evening session, supported by an administration hub. ${ }^{31}$ The service was designed collaboratively with public and patient engagement, the local CCG and local NHS healthcare providers. ${ }^{12}$ The overall service consists of the following elements by a single provider that bridged primary and secondary care:

- A consultant-led multidisciplinary clinic. Provided from initially five Primary Care resource centresthen extending to seven due to service demands. The clinics run from 10:00-18:00 hours. The clinic offers diagnosis spirometry and diagnosis and optimisation of COPD. The clinic now provides one Saturday morning clinic a month and a weekly evening clinic which runs up until 20:00.

- Rapid response service-Nurse-led service where patients experiencing an exacerbation of COPD can self-refer for assessment, via a free phone number, for initiation of acute treatment and monitoring. The service provides a 2-hour response for those at risk of hospital admission, with the aim to avoid unwarranted admissions. This service is provided 08:00-22:00 hours with an overnight on-call service 7 days a week.

- Early supported discharge-Patients who have been to accident and emergency or been admitted into hospital with an exacerbation of COPD can be referred into the service for additional support to facilitate an earlier discharge from hospital. This service is provided 08:00-22:00 hours 7 days a week.

- Home Oxygen and Review Service (HOSAR) - The HOSAR provides assessment and review of patients' home oxygen requirements, they review patients in the same community venues as the consultant-led clinics as well as providing home visits. This service is provided Monday to Friday, 10:00-18:00 hours.

- PR and physiotherapy-The PR team cover the main areas of Knowsley, for patients who have functional limitation due to the dyspnoea or who have had a recent hospital admission due to COPD. PR is provided 5 days a week 10:00-18:00 hours. The team also provides assessment and treatment for patients who have difficulty in clearing their sputum or who are struggling with managing their dyspnoea, this service is provided 7 days a week 10:00-18:00 hours.

- Palliative care-The KCOPD service provides assessment and review for patients who maybe entering the palliative phase of their condition to ensure effective symptom management.

- Counselling service-The KCOPD service has a dedicated respiratory counsellor who offers treatment and support for patients struggling with anxiety and depression or struggling with the impact of their condition on their life. This element of the service runs Monday to Friday, 10:00-18:00 hours.

The service is available to residents in Knowsley through GP referral. ${ }^{12}$ Patients are seen within 10 days of referral. Once known to the service, if they have been provided with a confirmed diagnosis of COPD, they can access any element of the services at any time without being rereferred by their GP. Knowsley GP referral trends to the KCOPD data show a dramatically decreasing trend (online supplementary appendix 3). From 2010/2011 to 2016/2017 (financial year), the clinic has provided care to almost 5500 patients. ${ }^{12}$ Clinic attendance has been variable, particularly at the outset of the service (with non-attendance as high as 20\%) stabilising to around $10 \%-12 \%$ from 2015 onwards. ${ }^{12}$ Initially, the service was contracted for 3 years, at a total value of $£ 4991667$.

\section{Statistical analysis}

Our sample size was predetermined based on the number of LSOAs in the intervention area and the number of matched LSOAs. Prior to our analysis, we estimated the effect size that the study would be able to detect with an $80 \%$ power by running multiple simulations of the planned analysis. ${ }^{32} 33$ This indicated that the effect size for this study at $80 \%$ power to detect, was around a $10 \%-11 \%$ decline in emergency admission rates per year associated with the intervention (see online supplementary appendix 4).

Characteristics of the intervention and control populations prior to the intervention were initially compared with assess the balance achieved between the groups. Additionally, the parallel trends assumption was tested using graphical methods and regression models to compare trends in the outcomes of interest between the intervention and control populations in the preintervention period.

To estimate the difference-in-differences, that is, the difference between the change in outcomes before and after the intervention in the intervention population compared with the change in outcomes over the same time periods in the control population, we include a treatment by period interaction term in a linear regression model. To control for potential demographic and socioeconomic changes which may confound the result we included annual LSOA data on unemployment rates, the percentage of the population that were female and the percentage aged 50+years in the model. We included a trend term for time to account for the long term trend in admission rates across the intervention and comparison groups and an additional spline term to account for any change in overall trends across both groups after the intervention. In sensitivity analysis, we estimated a model removing the spline term-that is, just including an annual trend term. We also included a random intercept for each LSOA to account for the longitudinal nature of the data (see box 1 for full details of the statistical model).

\section{Robustness tests}

We investigated the presence of unobserved confounding by repeating the analysis using an outcome that would not be expected to be influenced by the COPD intervention, that is, emergency admissions for gastrointestinal (GI) infections. We also investigated whether the effect of 


\section{Box 1 Model formula}

Equation for multivariable mixed effects linear regression model for chronic obstructive pulmonary disease (COPD) emergency admissions $Y_{\mathrm{ij}}=\beta_{0 \mathrm{j}}+\beta_{1 \mathrm{j}} t_{\mathrm{ij}}+\beta_{2 \mathrm{j}} T_{\mathrm{ij}}+\beta_{3 \mathrm{j}}$ Age $_{\mathrm{ij}}+\beta_{4 \mathrm{j}}$ Sex $_{\mathrm{ij}}+\beta_{5 \mathrm{j}}$ Unemployment $_{\mathrm{ij}}+$ $\beta_{6 \mathrm{j}}$ Treatment $_{\mathrm{ij}}+$

$\beta_{7 j}$ Period $_{\mathrm{ij}}+\beta_{8 \mathrm{i}}$ Treatment $_{\mathrm{ij}}$ Period $_{\mathrm{ij}}+\varepsilon_{\mathrm{ij}}$

Where $Y_{\mathrm{ij}}$ is the COPD emergency admission rate per 100000 population for lower super output areas (LSOA) $i$ at year $j$. The intercept $\beta_{0 \mathrm{j}}$ contains a random effect term and thus varies across years. $t$ is an annual time-trend term (spline 1). $T$ is a time-trend term (spline 2) which captures the change in trend from year 2011, and is equal to zero prior to 2010. Age is the per cent of the population aged 50+ years. Sex is the per cent of the population who are female. Unemployment is the per cent of the working age population (aged 16-64 years) claiming Jobseeker's Allowance or Universal Credit principally for the reason of being unemployed. Treatment indicates whether LSOA $i$ is a Knowsley or control LSOA (Knowsley=1; control=0). Period indicates whether year $j$ occurs post or preintervention (postintervention $=1$; preintervention=0). Treatment ${ }^{*}$ Period is the difference-in-differences estimator.

the intervention was different in more deprived LSOAs compared with less deprived LSOAs within Knowsley, and whether the effect differed between men and women. Analyses were conducted using R (V.3.4.3).

\section{Patient involvement}

The research question was developed through a collaboration involving local health service providers, public advisors and researchers. Public advisors are members of the public and/or service users who have knowledge of KCOPD and the locality in which it is delivered. The public advisors were involved in a series of meetings agreeing the focus for the research and the planned analysis. Three of the public advisors (TC, KW and AP) are coauthors of this paper and have contributed to the drafting of the paper and the interpretation of the results.

\section{RESULTS}

Characteristics of the Knowsley and matched control LSOAs in the preintervention period (2005-2010) are shown in table 2. Although the control areas at baseline were statistically significantly different from the intervention areas on a number of characteristics, these differences are relatively small and the difference-in-differences method accounts for these fixed differences in the analysis. The control areas were all also areas with high levels of deprivation and COPD emergency admissions. This is particularly the case when compared with the unmatched sample of North West LSOAs (see table 3 for characteristics of unmatched sample).

Trends in COPD emergency hospital admission rates per year for the Knowsley and control population are shown in figure 1 . In the preintervention period, emergency admission rates were slightly higher for Knowsley compared with the control population, and parallel trends in the rates were apparent between the two groups. Following the introduction of the intervention in 2011, admission rates for Knowsley decreased to levels observed in the control population. After the second year of the intervention, however, the admission rates appeared to have increased again in Knowsley compared with the control population (also see table 4 for annual emergency admission rates in the two groups).

Results from the difference-in-differences analysis for emergency admission rates are shown in table 5. The

Table 2 Characteristics of Knowsley and matched control LSOAs in preintervention period (2005-2010)

\begin{tabular}{|c|c|c|c|}
\hline & \multirow{2}{*}{$\begin{array}{l}\text { Knowsley LSOAs } \\
\text { (no=98) } \\
\text { Mean (SD) }\end{array}$} & \multirow{2}{*}{$\begin{array}{l}\begin{array}{l}\text { Control LSOAs } \\
\text { (no=392) }\end{array} \\
\text { Mean (SD) }\end{array}$} & \multirow[b]{2}{*}{ P value } \\
\hline & & & \\
\hline IMD score & $41.99(20.65)$ & $37.96(21.35)$ & $<0.001$ \\
\hline Distance to hospital with A\&E (km) & $5.47(2.5)$ & $5.36(2.84)$ & 0.401 \\
\hline Working age population unemployed (\%) & $4.99(2.76)$ & $4.54(2.97)$ & 0.001 \\
\hline GPs per 1000 population & $0.64(0.12)$ & $0.63(0.13)$ & 0.002 \\
\hline Population (number) & $1508.79(244.92)$ & $1496.45(246.56)$ & 0.702 \\
\hline Female population (number) & $792.08(129.75)$ & $779.55(129.69)$ & 0.032 \\
\hline Population aged $50+$ years (number) & $496.81(109.49)$ & 499.59 (119.93) & 0.610 \\
\hline QOF: COPD prevalence (\%) & $3.07(0.33)$ & $2.84(0.63)$ & $<0.001$ \\
\hline QOF: smoking prevalence (\%) & $25.83(4.77)$ & $24.82(5.45)$ & $<0.001$ \\
\hline $\begin{array}{l}\text { QOF: those with COPD receiving inhaled treatment whose inhaler } \\
\text { technique has been checked (\%) }\end{array}$ & $88.13(9.21)$ & $89.06(5.06)$ & $<0.001$ \\
\hline Emergency admissions for COPD per 100000 population per year & $519.99(402.33)$ & $468.46(389.75)$ & 0.004 \\
\hline
\end{tabular}

*Statistical significance of the difference between the groups tested using t-tests for normally distributed variables, or the Man-Whitney $U$ test as a non-parametric equivalent.

$\mathrm{A \& E}$, accident and emergency department; COPD, chronic obstructive pulmonary disease; GP, general practitioner; IMD, Index of Multiple Deprivation; LSOA, lower-layer super output area; QOF, quality and outcomes framework. 
Table 3 Characteristics of the intervention area and unmatched North West areas

\begin{tabular}{|c|c|c|c|}
\hline & \multirow{2}{*}{$\begin{array}{l}\text { Knowsley LSOAs } \\
\text { (no=98) }\end{array}$} & \multirow{2}{*}{$\begin{array}{l}\text { North west LSOAs } \\
\text { (no=4381) } \\
\text { Mean (SD) } \\
\end{array}$} & \multirow[b]{2}{*}{$P$ value } \\
\hline & & & \\
\hline GPs per 1000 population & $0.64(0.12)$ & $0.60(0.12)$ & $<0.001$ \\
\hline Working age population unemployed (\%) & $4.99(2.76)$ & $3.05(2.43)$ & $<0.001$ \\
\hline $\begin{array}{l}\text { QOF: those with COPD receiving inhaled treatment whose inhaler } \\
\text { technique has been checked }(\%)\end{array}$ & $88.13(9.21)$ & $91.36(3.88)$ & 0.188 \\
\hline Population (no) & $1508.79(244.92)$ & $1547.64(269.78)$ & $<0.001$ \\
\hline Female population (no) & $792.08(129.75)$ & $789.59(137.30)$ & 0.452 \\
\hline
\end{tabular}

Characteristics of Knowsley and unmatched North West LSOAs in preintervention period (2005-2010).

*Statistical significance of the difference between the groups tested using t-tests for normally distributed variables, or the Man-Whitney $\mathrm{U}$ test as a non-parametric equivalent.

COPD, chronic obstructive pulmonary disease; GP, general practitioner; IMD, Index of Multiple Deprivation; LSOA, lower-layer super output area; QOF, quality and outcomes framework.

coefficient for the difference-in-differences estimator indicates that on average the intervention was associated with a non-statistically significant reduction of 24 emergency COPD admissions per 100000 per year (95\% CI -10.6 to $58.8, \mathrm{p}=0.14$ ) in Knowsley compared with the control population following the introduction of the intervention. (see table 6 full model output). This was equivalent to a $5 \%$ decline in emergency admissions. We found that the intervention had no statistically significant effect on reducing length of stay per emergency COPD admissions, or emergency readmission rates (table 7).

Analysing the differential effects of the intervention by deprivation and by gender we found some evidence that these effects differed across these sub groups (online

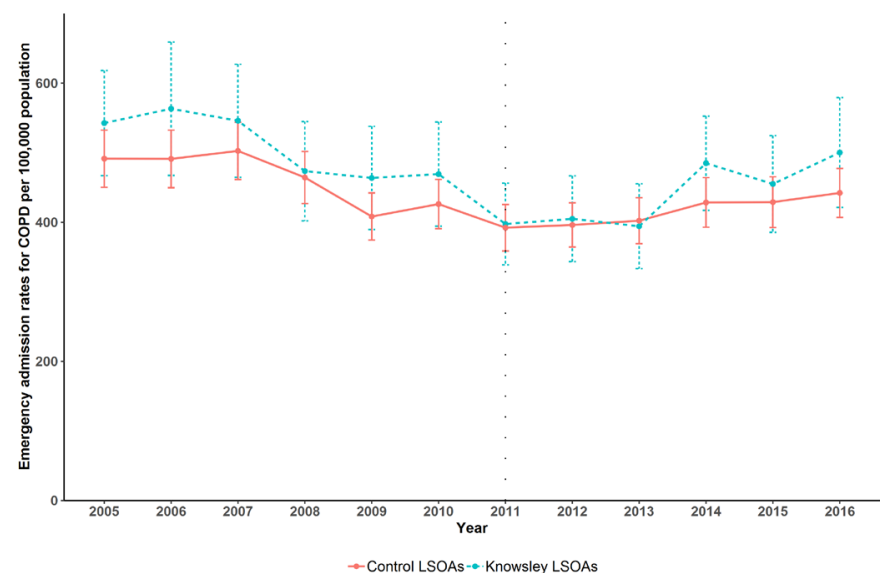

Figure 1 Trends in COPD emergency hospital admission rates per year, by Knowsley and matched control LSOAs, 2005-2016. COPD, chronic obstructive pulmonary disease; LSOAs, lower super output areas. supplementary appendix 5). The intervention had no statistically significant effect on emergency admissions in populations with low (table 8 ) and high (table 9) levels of income deprivation. Although there was some evidence to suggest that the intervention was associated with 64 fewer emergency admissions per 100000 per year $(95 \%$ CI 1.8 to $126.9, \mathrm{p}=0.044$ ) for populationswith medium levels of income deprivation (table 10). Furthermore, for men the intervention was associated with a reduction of 60 admissions per 100000 per year (95\% CI 12.3 to 107.3, $\mathrm{p}=0.014$; table 11 ), but there were no statistically significant effect for women (table 12).

\section{Robustness tests}

We found that during the preintervention period there was no significant difference in trends in emergency admission rates between Knowsley and the control population (online supplementary appendix 6), suggesting that the parallel trend assumption was not violated in this analysis. We found that there was no effect when running the analysis using an outcome (emergency admissions for GI infections) that would not plausibly be influenced by the intervention but could have been influenced by unobserved confounding (online supplementary appendix 6). Estimating a model removing a spline term allowing for a change in trend across both groups after the intervention did not change the results (online supplementary appendix 6).

\section{DISCUSSION}

\section{Principal findings}

We found that an integrated, consultant-led, multicomponent, community-based service was associated with a small 
Table 4 Emergency admission rates for COPD per 100000 population per year

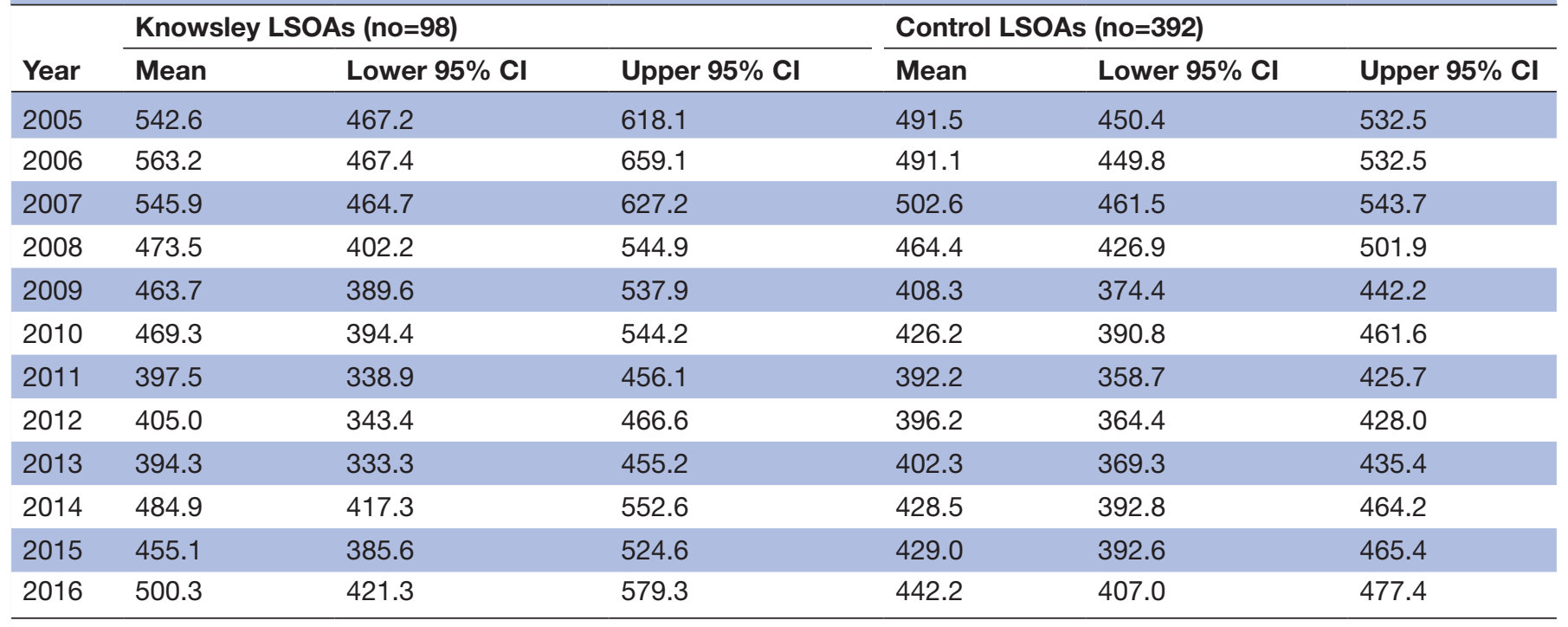

COPD, chronic obstructive pulmonary disease; LSOA, lower-layer super output area.

decline in emergency admissions for COPD, however, this is not statistically significant at the $5 \%$ level. Subgroup analysis indicated that the intervention may have been effective at reducing emergency admissions for men, and for people living within neighbourhoods that were of intermediate levels of deprivation for Knowsley.

\section{Strengths and limitations}

Our study has a number of strengths. First, we calculated the KCOPD in its real-life implementation setting, which makes our findings potentially more externally valid than those set in a trial context. Second, the service has been in operation for several years giving a long follow-up period of 5 years. This allowed us to look at whether effects were sustained. Third, we applied a combination of quasiexperimental methods-propensity score matching and difference-in-differences, which provide causal estimates of the intervention if the trends in outcomes would have been parallel in the absence of the intervention. Our approach provides a reasonably large effective sample size of 5880 observations providing reasonable power to identify relatively small effects.
However, some limitations remain. We cannot rule out the possibility that different trends in unobserved confounding factors between the two groups may have influenced the results. Although there are clear differences between the intervention and control groups, time invariant differences between the two groups could not bias the results due to the difference-in-differences methods. ${ }^{34}$ The reasons for matching was to identify groups that were likely to follow a similar trend over time, which was confirmed by assessing the parallel nature of the trends in outcomes before the intervention. We additionally controlled for a number of observed confounders. Unobserved confounders therefore could only bias the results if they followed different time trends over time between the intervention and control groups. When repeating the analysis using an outcome that would not plausibly be influenced by the intervention (emergency admissions for GI infections) but could have been influenced by unobserved confounding, such as changes health service admission thresholds or health provider financial incentives, we found no significant effect of the

Table 5 Result of difference-in-differences analysis showing the change in COPD emergency admissions per 100000 population in Knowsley following the intervention relative to the control group, 2005-2016

\begin{tabular}{lcccc}
\hline & Coefficient & Lower 95\% Cl & Upper 95\% Cl & $\mathbf{P}$ value \\
\hline Treatment (Knowsley=1; control=0) & 37.99 & -14.39 & 90.37 & 0.155 \\
Period (postintervention=1; preintervention=0) & -20.03 & -49.18 & 9.12 & 0.178 \\
DiD estimator (treatment*period) & -24.10 & -58.79 & 10.59 & 0.173 \\
\hline
\end{tabular}

Model based on equation shown in online supplementary file and includes random intercept for LSOA, and fixed effects for per cent of population aged 50+ years, per cent female, per cent unemployed and two spline terms for time (full model results are given in online supplementary file).

Model based on 98 Knowsley and 392 control LSOAs, and 5880 observations.

COPD, chronic obstructive pulmonary disease; DiD, difference-in-differences; LSOA, lower-layer super output area. 
Table 6 Full model output for main results

\begin{tabular}{lccrr|} 
& Coefficient & Lower 95\% Cl & Upper 95\% Cl & P value \\
\hline Spline 1 & -34.44 & -40.91 & -27.98 & $<0.001$ \\
Spline 2 & 63.02 & 52.99 & 73.05 & $<0.001$ \\
Population aged 50+ years (\%) & 6.07 & 3.75 & 8.40 & $<0.001$ \\
Population female (\%) & 10.23 & 3.33 & 17.12 & 0.004 \\
Working age population unemployed (\%) & 263.13 & 212.90 & 313.36 & $<0.001$ \\
Treatment (Knowsley=1; control=0) & 37.99 & -14.39 & 90.37 & 0.155 \\
\hline Period (postintervention=1; preintervention=0) & -20.03 & -49.18 & 9.12 & 0.178 \\
\hline DiD estimator (treatment ${ }^{\star}$ period) & -24.10 & -58.79 & 10.59 & 0.173
\end{tabular}

Model based on equation shown above and includes random intercept for LSOA.

Model based on 98 Knowsley and 392 control LSOAs, and 5880 observations.

Result of difference-in-differences analysis showing the change in COPD emergency admissions per 100000 population in Knowsley

following the intervention relative to the control group, 2005-2016.

*Variable entered into model in units of $10 \%$ points.

COPD, chronic obstructive pulmonary disease; DiD, difference-in-differences; LSOA, lower-layer super output area.

Table 7 Impact on length of stay per emergency admission and emergency readmission rates

\section{Coefficient Lower $95 \% \mathrm{Cl} \quad$ Upper $95 \% \mathrm{Cl} \quad$ P value}

Result of difference-in-differences analysis showing the change in length of stay in days per emergency COPD admission in Knowsley following the intervention relative to the control group, 2005-2016

$\begin{array}{lcccc}\text { Spline } 1 & 0.06 & -0.48 & 0.6 & 0.828 \\ \text { Spline 2 } & -0.75 & -1.55 & 0.05 & 0.065 \\ \text { Population aged 50+ years (\%) } & 0.11 & 0 & 0.21 & 0.046 \\ \text { Population female (\%) } & 0.03 & -0.31 & 0.36 & 0.868 \\ \text { Working age population unemployed (\%) }^{*} & -1.11 & -3.67 & 1.45 & 0.395 \\ \text { Treatment (Knowsley=1; control=0) } & 0.26 & -1.92 & 2.45 & 0.813 \\ \begin{array}{l}\text { Period (postintervention=1; } \\ \text { preintervention=0) }\end{array} & -1.65 & -4.25 & 0.94 & 0.211 \\ \text { DiD estimator (treatment }{ }^{*} \text { period) } & -0.95 & -3.98 & 2.08 & 0.538\end{array}$

Result of difference-in-differences analysis showing the change in COPD emergency readmissions per 100000 population in Knowsley following the intervention relative to the control group, 2005-2016

\begin{tabular}{lcccc} 
Spline 1 & -5.77 & -7.72 & -3.81 & $<0.001$ \\
\hline Spline 2 & 3.73 & 0.73 & 6.74 & 0.015 \\
\hline Population aged 50+ years (\%) & 0.21 & -0.31 & 0.73 & 0.43 \\
\hline Population female (\%) & 1.01 & -0.55 & 2.58 & 0.204 \\
\hline Working age population unemployed (\%) & 25.44 & 13.66 & 37.22 & $<0.001$ \\
\hline Treatment (Knowsley=1; control=0) & -1.6 & -11.46 & 8.25 & 0.749 \\
$\begin{array}{l}\text { Period (postintervention=1; } \\
\text { preintervention=0) }\end{array}$ & 4.21 & -4.94 & 13.36 & 0.367 \\
\hline DiD estimator (treatment ${ }^{*}$ period) & 3.39 & -7.37 & 14.14 & 0.537 \\
\hline
\end{tabular}

Model includes random intercept for LSOA.

Model based on 71 Knowsley and 268 control LSOAs, and 4068 observations.

Model based on 69 Knowsley and 266 control LSOAs, and 4020 observations.

LSOAs which had zero COPD emergency admissions for any year of the study period were removed when analysing the emergency readmission rate outcome.

LSOAs which had zero COPD emergency admissions for any year of the study period were removed when analysing the length of stay outcome, since length of stay was not applicable when zero admissions occurred.

*Variable entered into model in units of $10 \%$ points.

COPD, chronic obstructive pulmonary disease; DiD, difference-in-differences; LSOA, lower-layer super output area. 
Table 8 Result of difference-in-differences analysis showing the change in COPD emergency admissions per 100000 population in Knowsley following the intervention relative to the control group, for areas with low income deprivation, 20052016

\begin{tabular}{|c|c|c|c|c|}
\hline & Coefficient & Lower $95 \% \mathrm{Cl}$ & Upper $95 \%$ Cl & $P$ value \\
\hline Treatment (Knowsley=1; control=0) & -15.78 & -65.11 & 33.54 & 0.528 \\
\hline Period (postintervention $=1$; preintervention $=0$ ) & -25.70 & -57.65 & 6.25 & 0.115 \\
\hline
\end{tabular}

Model includes random intercept for LSOA, and fixed effects for per cent of population aged 50+ years, per cent female, per cent unemployed and two spline terms for time (full model results are given in online supplementary file). Model based on 29 Knowsley and 135 control LSOAs, and 1968 observations.

COPD, chronic obstructive pulmonary disease; DiD, difference-in-differences; LSOA, lower-layer super output area.

intervention. We did not have access to data on other outcomes such as use of domiciliary oxygen, oral corticosteroids or out of hours calls and were only able to assess the impact of the intervention on emergency COPD hospital admissions, length of stay and emergency COPD readmission rates. While these outcomes may not fully reflect health benefits to the users of these services, they were the planned outcomes of the intervention agreed by the commissioner in their contract with the service provider. Finally, the ecological nature of this study limits the conclusions that can be drawn about individual-level factors, and the results reflect the population-level impact of the KCOPD.

\section{Meaning of the study: possible implications for adoption}

We found little evidence for an overall effect of the intervention with an initial decline in admissions not sustained throughout the follow-up period. There are a number of potential reasons why we fail to find clear evidence of effectiveness. First, our study was underpowered to detect a small effect. Our prior power calculations indicated that the study had sufficient power to detect a $10 \%$ decline in emergency admissions, if the effect was smaller than this the study may have failed to detect that effect. Second, it may have been the case that the effectiveness of the programme declined over time as is suggested in figure 1. This may be because as the service reached full capacity it was less able to fully accommodate patient needs. This was supported by reports from the service that they had to undergo a staff reorganisation in 2012 in order to meet demand more effectively. ${ }^{12}$ This is also supported by the trend in the rate of referrals from GP services-which were high in the first year but then decreased rapidly from 2013 (see online supplementary appendix 3). This could indicate that the service may have been effective in the initial 2 years as it saw people with existing COPD with unmet needs, in the following years, as only new suspected COPD patients were referred, the numbers reduced year on year. ${ }^{12}$

Some COPD interventions have been found to be less effective in deprived populations. ${ }^{130}$ However, the KCOPD we investigated varied in effectiveness across levels of deprivation as there was a greater effect on those patients from areas with medium levels of deprivation compared with high and low levels of deprivation within Knowsley. The borough of Knowsley is a very deprived area, therefore intermediate deprivation in Knowsley is still quite deprived when comparing nationally. The most deprived areas in Knowsley are within the most deprived $10 \%$ of areas nationally and are likely to include populations with multiple conditions as risk factors. ${ }^{35}$ As stated in previous research, ${ }^{3913}$ and due to the high levels of deprivation in Knowsley, patients with COPD may have had greater difficulty in accessing the service, found it harder to attend appointments or may have presented late with more advanced disease. All of these factors could limit effectiveness. It is unclear why the service would have been less effective in the more affluent areas of Knowsley which have similar levels of deprivation to the national

Table 9 Result of difference-in-differences analysis showing the change in COPD emergency admissions per 100000 population in Knowsley following the intervention relative to the control group, for areas with high income deprivation, 20052016

\begin{tabular}{|c|c|c|c|c|}
\hline & Coefficient & Lower $95 \% \mathrm{Cl}$ & Upper 95\% Cl & P value \\
\hline Treatment (Knowsley=1; control=0) & 43.22 & -36.52 & 122.95 & 0.286 \\
\hline Period (post-intervention $=1$; pre-intervention $=0$ ) & -50.36 & -112.14 & 11.41 & 0.110 \\
\hline
\end{tabular}

Model includes random intercept for LSOA, and fixed effects for per cent of population aged 50+ years, per cent female, per cent unemployed and two spline terms for time (full model results are given in online supplementary file).

Model based on 37 Knowsley and 125 control LSOAs, and 1944 observations.

COPD, chronic obstructive pulmonary disease; DiD, difference-in-differences; LSOA, lower-layer super output area. 
Table 10 Result of difference-in-differences analysis showing the change in COPD emergency admissions per 100000 population in Knowsley following the intervention relative to the control group, for areas with medium income deprivation, 2005-2016

\begin{tabular}{|c|c|c|c|c|}
\hline & Coefficient & Lower $95 \% \mathrm{Cl}$ & Upper $95 \% \mathrm{Cl}$ & $P$ value \\
\hline Treatment (Knowsley=1; control=0) & 18.88 & -60.48 & 98.25 & 0.639 \\
\hline Period (postintervention=1; preintervention=0) & 19.78 & -32.27 & 71.83 & 0.456 \\
\hline
\end{tabular}

Model includes random intercept for LSOA, and fixed effects for per cent of population aged 50+ years, per cent female, per cent unemployed and two spline terms for time (full model results are given in online supplementary file).

Model based on 32 Knowsley and 132 control LSOAs, and 1968 observations.

COPD, chronic obstructive pulmonary disease; DiD, difference-in-differences; LSOA, lower-layer super output area.

average. It may have been that lower burden of disease in these areas meant that there was less marginal benefit from the service. This indicates the importance of understanding the needs of the local population when developing similar services and the need to involve people from different population groups in their design. The recent local evaluation of the service, for example, highlighted that access and use could have been improved if services were located close to existing community services and public transport routes. ${ }^{12}$ Additionally, as there is a higher prevalence of COPD in more deprived areas, more COPD clinics are available which results in more visits with patients. Therefore, the same level of provision is provided in deprived areas but the availability of care is higher. ${ }^{12}$ However, nationally accessibility to services can be a postcode lottery as all services are commissioned differently.

It is possible that a reduction in admissions could be a cohort effect related to prior industrial exposure, however, this would likely lead to a more gradual decline, not the steep change we see at the intervention point. Comparisons between areas in Knowsley have shown no historic increase for the rate of hospital admissions where there was evidence of this exposure, ${ }^{22}$ suggesting that this is not leading to a decline as the exposed may have already died. Additionally, matched controls were from other deprived areas in the North West where industrial affects would be similar.

The intervention also appeared to be less effective among women. Some potential explanations of this may have been because women are: being diagnosed less than men as some clinicians see COPD as a 'man's disease'; ${ }^{35}$ being frequently undertreated for $\mathrm{COPD}^{36}$; finding it harder to quit smoking; ${ }^{37}$ andobtaining more damage to their lungs than men. ${ }^{38}$ Additionally, women are less likely to access services due to having multiple caring responsibilities and less time for treating their own health. ${ }^{39} 40$ Although more men smoke $(80: 20 \%)$, the similar mortality rate among men and women with COPD can be explained by a rapid deterioration of women once they begin smoking and more severe COPD disease. ${ }^{41}$ Women are more susceptible to developing COPD younger due to being more vulnerable to the social context of smoking. This is reflected in the rates of women smokers that has increased in recent years, ${ }^{1}$ and are notably higher within the Knowsley region. ${ }^{519}$ Additionally, a poorer quality of life has been reported more frequently in women than in men with COPD due to biological and genetic factors ${ }^{42}$ along with more hospitalisation. ${ }^{43}$ However, the extent to which susceptibility and vulnerability contribute and interact to explain gender differences for COPD development and its severity is largely under-reported. Future initiatives should therefore consider gender-specific issues, such as differential incidences of comorbid conditions, a higher risk of exacerbations and higher symptom burden. Smoking cessation management and COPD treatment should be specifically tailored to individual women and reviewed regularly to optimise patient outcomes. Furthermore, education should be an integral part of COPD for women, as it may help to empower them to take control of their disease.

Table 11 Result of difference-in-differences analysis showing the change in COPD emergency admissions per 100000 women in Knowsley following the intervention relative to the control group, 2005-2016

\begin{tabular}{|c|c|c|c|c|}
\hline & Coefficient & Lower $95 \% \mathrm{Cl}$ & Upper $95 \%$ Cl & $P$ value \\
\hline Treatment (Knowsley=1; control=0) & 45.48 & -17.81 & 108.77 & 0.159 \\
\hline Period (postintervention $=1$; preintervention $=0$ ) & -16.43 & -57.40 & 24.54 & 0.432 \\
\hline
\end{tabular}

Model includes random intercept for LSOA, and fixed effects for per cent of population aged 50+ years, per cent female, per cent unemployed and two spline terms for time (full model results are given in online supplementary file). Model based on 98 Knowsley and 392 control LSOAs, and 5880 observations.

COPD, chronic obstructive pulmonary disease; DiD, difference-in-differences; LSOA, lower-layer super output area. 
Table 12 Result of difference-in-differences analysis showing the change in COPD emergency admissions per 100000 men in Knowsley following the intervention relative to the control group, 2005-2016

\begin{tabular}{lcccc}
\hline & Coefficient & Lower 95\% Cl & Upper 95\% Cl & $\mathbf{P}$ value \\
\hline Treatment (Knowsley=1; control=0) & 18.50 & -37.07 & 74.07 & 0.513 \\
Period (postintervention=1; preintervention=0) & -22.72 & -62.63 & 17.19 & 0.264 \\
DiD estimator (treatment*period) & -59.80 & -107.29 & -12.32 & 0.014 \\
\hline
\end{tabular}

Model includes random intercept for LSOA, and fixed effects for per cent of population aged 50+ years, per cent female, per cent unemployed and two spline terms for time (full model results are given in online supplementary file). Model based on 98 Knowsley and 392 control LSOAs, and 5880 observations.

COPD, chronic obstructive pulmonary disease; DiD, difference-in-differences; LSOA, lower-layer super output area.

Since implementing the KCOPD service, the service has been expanded to include asthma, community acquired pneumonia (that has higher admission rates), is working closely with the Knowsley CVD (KCVD). Additionally, they have introduced respiratory clinics in the local addiction services to target difficult to reach groups and are offering in-house smoking cessation. The service has also expanded the early supported discharge element of the service to base staff within the local emergency departments to review patients as soon as they arrive at hospital. Further research is needed to examine the impact of the expansion of the service on emergency admissions, length of inpatient stay and readmissions.

The evidence for recent integration initiatives in the UK has tended to rely on evaluations that have not used quasiexperimental or experimental designs; thus providing limited evidence of impact. ${ }^{44} 45$ Our findings indicate that the KCOPD model of out of hospital treatment for COPD may have had limited or no impact on overall emergency admission rates, although it may have been more effective for some population groups. This appears to have been because effects were not sustained over the long term. This highlights the importance of designing out of hospital services so they address the different needs of particular population segments and are sufficiently resourced to sustain access over the long term.

\section{Author affiliations}

${ }^{1}$ Psychology, Liverpool John Moores University, Liverpool, UK

${ }^{2}$ Public Health and Policy, University of Liverpool, Liverpool, UK

${ }^{3}$ Department of Molecular and Clinical Pharmacology, University of Liverpool,

Liverpool, UK

${ }^{4}$ Clinical Trials Unit/Clinical Quality, Liverpool Heart \& Chest Hospital NHS Foundation

Trust, Liverpool, UK

${ }^{5}$ Clinical Trials Unit/Clinical Quality, Liverpool Heart and Chest Hospital NHS

Foundation Trust, Liverpool, UK

${ }^{6}$ Adult CF centre, The Liverpool Heart and Chest Hospital, Liverpool, UK

${ }^{7}$ Institute of Psychology, Health and Society, University of Liverpool, Liverpool, UK

\section{Twitter Pooja Saini @poojaliverpool}

Acknowledgements The authors thank Liverpool Heart and Chest NHS Foundation Trust, Knowsley Clinical Commissioning Group, Knowsley Council, and the public advisors who contributed to the study.

Contributors PS and BB conceived the study design. All the team developed the study and contributed to finalising the research question (PS, TR, JD, BM, SP, AP, $\mathrm{LMH}, \mathrm{TR}, \mathrm{KW}, \mathrm{KD}$ and BB). Analysis (TR and BB) indicators (KD) local data (MS). BM and SP supported this work providing information of the nature of the intervention, contextual information and fact-checking the final draft. PS, TR and BB drafted the manuscript and all other authors (JD, BM, SP, AP, LMH, TR, KW and KD) critically assessed and contributed to the paper and agreed the final manuscript. We would like to thank the public advisors (AP, TC and KW) who contributed throughout the paper and we look forward to continuing our work with them in the future. $B B$ is guarantor for the study. The corresponding author attests that all listed authors meet authorship criteria and that no others meeting the criteria have been omitted.

Funding The study was part-funded by the National Institute for Health Research Collaboration for Leadership in Applied Health Research and Care North West Coast (NIHR CLAHRC NWC) (Grant/Award Number: CLAHRC-NWC-167) and Liverpool Heart and Chest Hospital NHS Trust.

Disclaimer The views expressed are those of the author(s) and not necessarily those of the NHS, the NIHR or the Department of Health and Social Care. The views expressed in this manuscript are those of the author and do not represent Liverpool Heart and Chest NHS Foundation Trust. There are no other relationships or activities that could appear to have influenced the submitted work.

Competing interests This study was supported by the National Institute for Health Research Collaboration for Leadership in Applied Health Research and Care North West Coast (NIHR CLAHRC NWC). All authors have completed the ICMJE uniform disclosure form at www.icmje.org/coi_disclosure.pdf (available on request from the corresponding author) and declare: BM and SP are employed by Liverpool Heart and Chest NHS Foundation Trust the provider of KCOPD and were involved in providing information about the nature of the intervention and providing contextual information on request when interpreting the results. AP is an elected governor and KW is employed as patient ambassador at Liverpool Heart and Chest NHS Foundation Trust, both were involved as a public advisors. They had no role in the analysis or presentation of the results.

Patient consent for publication Not required.

Provenance and peer review Not commissioned; externally peer reviewed.

Data availability statement Data may be obtained from a third party and are not publicly available. All data relevant to the study are included in the article or uploaded as online supplementary information. The manuscript's guarantor (BB) affirms that the manuscript is an honest, accurate and transparent account of the study being reported; that no important aspects of the study have been omitted; and that any discrepancies from the study as planned have been explained.

Open access This is an open access article distributed in accordance with the Creative Commons Attribution Non Commercial (CC BY-NC 4.0) license, which permits others to distribute, remix, adapt, build upon this work non-commercially, and license their derivative works on different terms, provided the original work is properly cited, appropriate credit is given, any changes made indicated, and the use is non-commercial. See: http://creativecommons.org/licenses/by-nc/4.0/.

ORCID iD

Pooja Saini http://orcid.org/0000-0002-4981-7914

\section{REFERENCES}

1 Department of Health and Social Care [DH and SC]. An Outcomes Strategy for COPD and Asthma. In: NHS Companion Document - $A$ new action plan for treatment of respiratory problems for the NHS. England: . NHS, 2012.

2 Health and Social Care Information Centre. Ccg outcome indicator set, 2016. Available: https://data.england.nhs.uk/dataset/nhsof-3- 
2-emergency-re-admissions-within-30-days-of-discharge-fromhospital[Accessed 23 Feb 18].

3 National COPD Audit Programme. Copd: working together. National chronic obstructive pulmonary disease (COPD) audit programme: clinical audit of COPD exacerbations admitted to acute hospitals in England and Wales 2017, 2018. Available: www.rcplondon.ac.uk/ working-together

4 British Lung Foundation. Chronic obstructive pulmonary disease (COPD) statistics, 2018. Available: https://statistics.blf.org.uk/copd [Accessed 23 Mar 19].

5 Joint Strategic Needs Assessment [JSNA] Report. Respiratory Disease. Knowsley Joint Strategic Needs Assessment Report, 2016. Available: http://knowsleyknowledge.org.uk/wp-content/uploads/ 2015/06/JSNA-Report-Respiratory-Final.pdf

6 Knowsley Public Health Annual Report Statistical Compendium. Knowsley public health annual report statistical compendium 2013/14, 2013. Available: http://www.knowsley.gov.uk/PDF/ knowsley-public-health-statistical-compendium-2013-14.pdf

7 Knowsley Public Health Annual Report. Knowsley public health annual report 2014/15, 2014. Available: https://www.knowsley.gov. uk/pdf/public-health-annual-report-2014-15.pdf

8 NHS England. Next steps on the NHS five year forward view. London: NHS England, 2017.

9 NHS England. The long term plan. England: NHS, 2019.

10 Shahab L, Jarvis MJ, Britton J, et al. Prevalence, diagnosis and relation to tobacco dependence of chronic obstructive pulmonary disease in a nationally representative population sample. Thorax 2006;61:1043-7.

11 Puhan MA, Gimeno-Santos E, Cates CJ, et al. Pulmonary rehabilitation following exacerbations of chronic obstructive pulmonary disease. Cochrane Database Syst Rev 2016;59.

12 Pilsworth S, Matata B, Shaw M, et al. A Service Evaluation into the effectiveness of the Knowsley Community Chronic Obstructive Pulmonary Disease Service. In: Liverpool heart and chest Hospital report, Knowsley, 2018.

13 Levin KA, Crighton EM. Reshaping care for older people: trends in emergency admissions to hospital during a period of simultaneous interventions in Glasgow City, April 2011-March 2015. Maturitas 2016;94:92-7.

14 British Thoracic Society. Impress; improving and integrating respiratory services., 2011. Available: https://www.networks.nhs.uk/ nhs-networks/impress-improving-and-integrating-respiratory

15 Griffiths TL, Phillips CJ, Davies S, et al. Cost effectiveness of an outpatient multidisciplinary pulmonary rehabilitation programme. Thorax 2001;56:779-84.

16 Wilkinson T, North M, Bourne SC. Reducing hospital admissions and improving the diagnosis of COPD in Southampton City: methods and results of a 12-month service improvement project. NPJ Prim Care Respir Med 2014;24:14035.

17 Robertson R, Sonola L, Honeyman M, et al. Specialists in out-ofhospital settings: findings from six case studies. London: The King's Fund, 2014.

18 Damery S, Flanagan S, Combes G. Does integrated care reduce hospital activity for patients with chronic diseases? an umbrella review of systematic reviews. BMJ Open 2016;6:e011952.

19 Nacul L, Soljak M, Samarasundera E, et al. Copd in England: a comparison of expected, model-based prevalence and observed prevalence from general practice data. $J$ Public Health 2011;33:108-16.

20 Office for National Statistics. Lower layer super output area population estimates (supporting information), 2018. Available: https://www.ons.gov.uk/peoplepopulationandcommunity/populati onandmigration/populationestimates/datasets/lowersuperoutputarea midyearpopulationestimates

21 Department for Communities and Local Government. The English Indices of Deprivation 2015: Statistical Release, 2015. Available: https://www.gov.uk/government/statistics/english-indices-ofdeprivation-2015 [Accessed 01 Sep 17].

22 Knowsley Health Advisory Group Report. Respiratory disease and lung cancer in Kirkby. Knowsley Council, NHS, 2008. Available: http://www.knowsley.gov.uk/pdf/Health\%20advisory\%20group\% 20report.pdf
23 Rosenbaum PR, RUBIN DB, Donald BR. The central role of the propensity score in observational studies for causal effects. Biometrika 1983;70:41-55.

24 Austin PC. An introduction to propensity score methods for reducing the effects of confounding in observational studies. Multivariate Behav Res 2011;46:399-424.

25 Dimick JB, Ryan AM. Methods for evaluating changes in health care policy: the difference-in-differences approach. JAMA 2014;312:2401-2.

26 Health and Social Care Information Centre. Indicator specification: Compendium of population health indicators - Emergency hospital admissions: all conditions, 2016. Available: https://digital.nhs.uk/ data-and-information/publications/clinical-indicators/compendiumof-population-health-indicators/compendium-hospital-care/current/ emergency-admissions

27 Health and Social Care Information Centre. Methodology to create provider and CIP spells from hES APC data, 2014. Available: https://indicators.hscic.gov.uk/download/Additional\%20Reading/ Methods\%20annexes/Compendium\%20User\%20Guide\% 202015\%20Feb\%20Annex\%2013\%20V1.pdf [Accessed 16 Jan 2018].

28 Downing J, Rose TC, Saini P, et al. Impact of a community-based cardiovascular service in an area of high deprivation. Heart 2019.

29 NHS digital. NHS digital, 2019. Available: https://digital.nhs.uk/ data-and-information/data-tools-and-services/data-services/ hospital-episode-statistics/hospital-episode-statistics-datadictionary

30 Health and Social Care Information Centre. Ccg outcome indicator set, 2016. Available: https://data.england.nhs.uk/dataset/nhsof-3-2emergency-readmissions-within-30-days-of-discharge-from-hospital [Accessed 23 Feb 2018].

31 Wise J. Nice recommends pulmonary rehabilitation programmes for patients with COPD. BMJ 2016;352:i768.

32 Feiveson AH. Power by simulation. Stata J 2002;2:107-24.

33 Curtis LA, Burns A. Unit costs of health and social care,Project report. University of Kent, 2018: 1-201. 10.22024/ UniKent/01.02.70995

34 Angrist JD, Pischke JS. Mostly Harmless Econometrics: An Empiricist's Companion. Princeton University Press, 2009.

35 Lamprecht B, Soriano JB, Studnicka M, et al. Determinants of underdiagnosis of COPD in national and international surveys. Chest 2015:148:971-85.

36 Ancochea J, Miravitlles M, García-Río F, et al. Underdiagnosis of chronic obstructive pulmonary disease in women: quantification of the problem, determinants and proposed actions. Arch Bronconeumol 2013;49:223-9.

37 Bohadana A, Nilsson F, Rasmussen T, et al. Gender differences in quit rates following smoking cessation with combination nicotine therapy: influence of baseline smoking behavior. Nicotine Tob Res 2003:5:111-6.

38 Sin DD, Cohen SB-Z, Day A, et al. Understanding the biological differences in susceptibility to chronic obstructive pulmonary disease between men and women. Proc Am Thorac Soc 2007:4:671-4

39 Lundsgaard J. Consumer Direction and Choice in Long-term Care for Older Persons, Including Payments for Informal Care, Health Working Paper No 20. Paris: OECD, 2005.

40 Himmelweit S, Land H. Reducing Gender Inequalities to Create a Sustainable Care System. York: Joseph Rowntree Foundation, 2008.

41 Barnett K, Mercer SW, Norbury M, et al. Epidemiology of multimorbidity and implications for health care, research, and medical education: a cross-sectional study. Lancet 2012;380:37-43.

42 Sansores RH, Ramírez-Venegas A. Women are both more susceptible and more vulnerable than men when it comes to COPD. Eur Respir J 2016;47:19-22.

43 de Torres JP, Casanova C, Hernández C, et al. Gender associated differences in determinants of quality of life in patients with COPD: a case series study. Health Qual Life Outcomes 2006;4:72.

44 National Institute for Health and Care Excellence [NICE]. Chronic obstructive pulmonary disease in over 16s: diagnosis and management. In: Clinical guideline [CG101, 2010.

45 National Institute for Health and Care Excellence [NICE]. Chronic obstructive pulmonary disease in adults. In: NICE quality standard QS10, 2016. www.nice.org.uk/guidance/qs10 